\title{
Pediatric Rheumatology Terminology
}

National Cancer Institute

\section{Source}

National Cancer Institute. Pediatric Rheumatology Terminology. NCI Thesaurus. Code C118468.

Terminology developed by a collaborative effort of the National Cancer Institute's Enterprise Vocabulary Services, the National Institute of Child Health and Human Development, and an international group of clinicians and informaticists to support the reporting of events observed in clinical care and research in children and adolescents seen by experts in diseases of joints, muscles, and bones. 